\title{
The Dependence of the Molecular First Hyperpolarizabilities of Merocyanines on Ground-state Polarization and Length
}

\author{
Rafael Ortiz, a Seth R. Marder, ${ }^{* a, b}$ Lap-Tak Cheng, ${ }^{c}$ Bruce G. Tiemann, ${ }^{a, b}$ Silvia Cavagnero ${ }^{d}$ and Joseph W. Zillere \\ a Molecular Materials Resource Center, The Beckman Institute, California Institute of Technology, Pasadena, \\ USA CA 91125 \\ b Jet Propulsion Laboratory, California Institute of Technology, 4800 Oak Grove Drive, Pasadena, USA CA 91109 \\ cE. I. Du Pont de Nemours \& Co., Inc., Experimental Station, P.O. Box 80356, Wilmington, Delaware, USA 19880-0356 \\ ¿Arthur Amos Noyes Laboratory of Chemical Physics, California Institute of Technology, Pasadena, USA CA 91125 \\ - Department of Chemistry, University of California, Irvine, USA CA 92717
}

We report here the dipole moment $(\mu)$ and first hyperpolarizability $(\beta)$ determined by electric field-induced second harmonic generation, for several merocyanine dyes containing an 1,3,3-trimethylindoline heterocycle as a 'donor' in which the 'acceptor' end of the molecule and the polyene bridge length was systematically varied; dyes with hexamethine bridges gave positive $\beta$, while that with a dimethine bridge gave a negative $\beta$ value.

We have hypothesized that the ground-state polarization and bond length alternation (BLA) (i.e. the difference between average length of carbon-carbon double and single bonds in a polymethine chain) are useful parameters to consider when establishing structure-property relationships for nonlinear optical (NLO) molecules. ${ }^{1-3}$ Electric field dependent calculations on $\mathrm{Me}_{2} \mathrm{~N}-(\mathrm{CH}=\mathrm{CH})_{4}-\mathrm{CHO}$ show that with increasing applied electric field the geometry of the molecule changes from the neutral polyene structure (BLA $\geqslant-0.12 \AA$ ) on the left in Fig. 1, to a polar cyanine-like structure (BLA $=0 \AA$ ) and to a highly polar zwitterionic polyene structure (BLA ca. $0.05 \AA) .{ }^{3}$ Also, as the value of BLA changes from negative to positive, the ground-state dipole moment, $\mu$, increases and, at the same time, the first molecular hyperpolarizability, $\beta$, initially increases, reaches a maximum and begins to decrease, crossing through zero at BLA $=0 \AA$, and ultimately becomes negative when BLA is positive. The above dependence of $\beta$ on the ground-state polarization and BLA for a series donoracceptor substituted polyenes was recently demonstrated experimentally. ${ }^{4}$ Most donor-acceptor substituted $\pi$-conjugated molecules, such as stilbenes and polyenes, have positive $\beta$-values that increase as the strength of donors and acceptors increase and the ground-state dipole moment increases. ${ }^{5-8}$

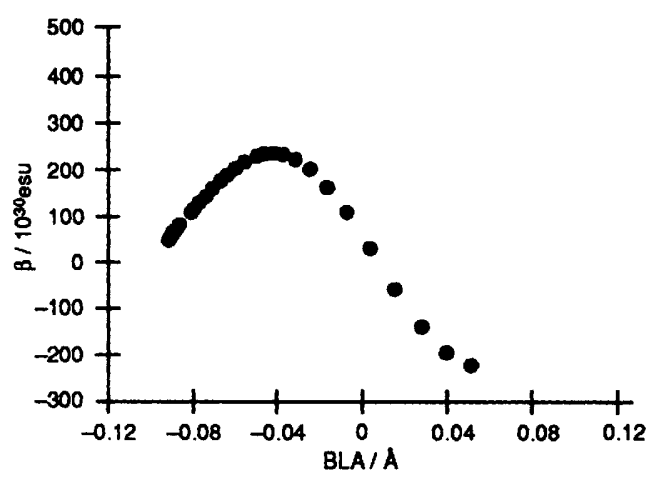

Fig. 1 Plot of $\beta$ versus BLA for $\mathrm{Me}_{2} \mathrm{~N}-(\mathrm{CH}=\mathrm{CH})_{4}-\mathrm{CHO}$, data taken from ref. 4
We have undertaken a study of merocyanines containing various end groups and bridge lengths to test the generality of the types of curves shown in Fig. 1 and to develop useful molecules for electro-optic poled polymer applications. Here we report results from an electric field induced second harmonic generation (EFISH) ${ }^{9}$ study to determine $\beta$ on a series of compounds where we varied the acceptor strength and the bridge length while maintaining the donor (an indoline heterocycle) constant (Fig. 2). In this manner, we were able to tune the extent of ground-state polarization (and BLA) of our molecules. The syntheses of the merocyanines 1-3 were performed using published procedures 10 and compounds 4-6 were prepared in manner analogous to that for 3 . The
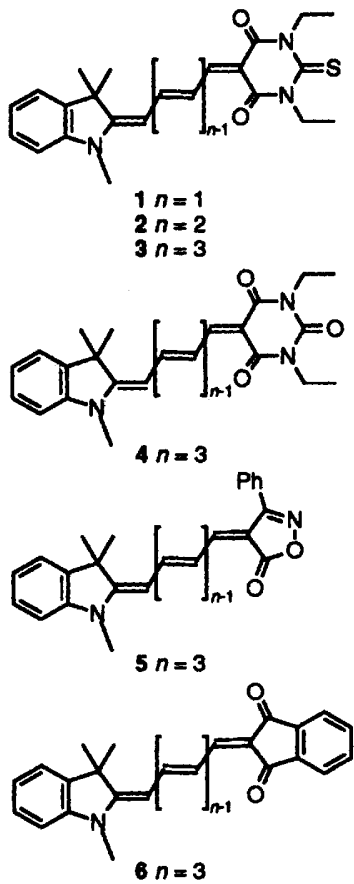

Fig. 2 Structures of merocyanines examined in this study

Table 1. Selected linear and nonlinear optical properties for 1-6 measured in chloroform. EFISH values were determined using $1.907 \mu \mathrm{m}$ fundamental radiation.

\begin{tabular}{lllcrrr}
\hline Compound & $\lambda_{\max } / \mathrm{nm}$ & $\log \varepsilon / \mathrm{dm}^{3} \mathrm{~mol}^{-1} \mathrm{~cm}^{-1}$ & $\mu / 10^{-18}$ esu & $\beta / 10^{-30}$ esu & $\beta(0) / 10^{-30}$ esu & $\mu \cdot \beta / 10^{-48}$ esu \\
\hline $\mathbf{1}$ & 494 & 5.1 & 7.4 & -46 & -31 \\
$\mathbf{2}$ & 592 & 5.3 & 8.9 & 52 & 28 \\
$\mathbf{3}$ & 686 & 5.3 & 9.1 & 300 & 120 \\
$\mathbf{4}$ & 664 & 5.0 & 11 & 280 & 126 \\
$\mathbf{5}$ & 648 & 5.1 & 6.9 & 360 & 171 \\
$\mathbf{6}$ & 658 & 5.0 & 4.4 & 500 & 2730 & 230 \\
\hline
\end{tabular}




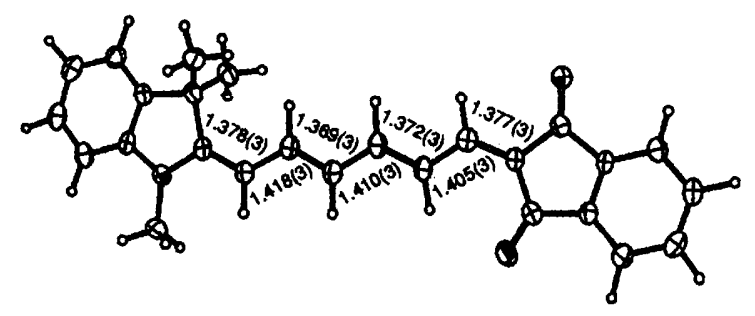

Fig. 3 Thermal ellipsoid plot from an X-ray crystal determination for compound 6 with bond lengths $(\AA)$ in the hexamethine bridge shown

compounds were purified by recrystallization and then characterized by UV-VIS, ${ }^{1} \mathrm{H}$ and selective $1 \mathrm{D}$-TOCSY nuclear magnetic resonance (NMR) and mass spectrometry, as well as elemental analysis. $+\beta$ Values were measured in chloroform solution by EFISH, using $1.907 \mu \mathrm{m}$ fundamental radiation. 5.9 EFISH measurements at $1.064 \mu \mathrm{m}$ for compounds 1-3, measured in $\mathrm{Me}_{2} \mathrm{SO}$ were reported earlier, but since the second harmonic signal was extremely close in energy to that of dominant electronic absorption for the compounds the results are difficult to interpret. ${ }^{10}$

Table 1 shows the measured values of the optical absorption maximum $\left(\lambda_{\max }\right)$, the molar extinction coefficient $(\varepsilon)$, the dipole moment $(\mu), \beta$, the zero frequency form of $\beta[\beta(0)]$ corrected for dispersion using the two-state model ${ }^{11}$ and the dot product of $\beta$ and $\mu(\mu \cdot \beta)$ all measured in chloroform. Since the trimethylindoline moiety is a relatively weak heterocyclic donor, merocyanines 3-6 do not have exceptionally large dipole moments that are characteristic of zwitterionic compounds. These results suggest that they have negative BLA and are therefore consistent with the observed positive $\beta$ values. From previous studies we can rank the relative strength of the acceptors for compounds in Table 1 as follows: 1,3-diethylthiobarbituric acid $\approx 3$-phenyl-5-isoxazolone $>$ 1,3-diethylbarbituric acid $>1,3$-indanedione. ${ }^{12}$ Thus, molecules 3-6 have an unusual inverse acceptor strength-hyperpolarizability relationship, suggesting that molecules in this study are on the part of the BLA curve where $\beta$ is decreasing towards zero (which occurs at the BLA $=0 \AA$, cyanine limit). For example, 6, with the weakest acceptor, 1,3-indanedione, has the smallest $\mu$ and the largest $\beta$, whereas 3 and 5 with the strongest acceptors, 1,3-diethylthiobarbituric acid and 3-phenyl-5-isoxazolone have the largest $\mu$ and the smallest $\beta$. The BLA for polymethine bridge of 6 was obtained from the X-ray crystal structure (Fig. 3). Although it should be noted that the BLA in the moderately polar solvent for 6 may differ from that in the solid state due to the potentially strong internal fields in the crystal, the observed BLA of $-0.037 \AA \ddagger$ is close to the predicted BLA $(0.04-0.05 \AA)$ where $\beta$ is maximized. ${ }^{4}$

Since less work is required to separate charge over a shorter distance, for a given donor acceptor pair, it is expected that decreasing the length of the molecules will lead to a more zwitterionic structure, i.e. to more positive BLA. Thus, by decreasing the polyene bridge length from six methines for 3 to four methines for $2, \beta$ is expected to decrease both because of the decreased length, but also because the shorter molecule may have a BLA very close to the cyanine limit at which $\beta$ is ca. 0 . Accordingly, it is not surprising that $\beta(0)$ for 2 is more than a factor of four lower than that for 3 . Furthermore for compound 1, with a two methine bridge the molecule is polarized to a point where the zwitterionic form dominates, i.e. BLA is positive, and as a result 1 has a negative $\beta$ value.

To summarize, by systematically varying the acceptor group while maintaining a fixed donor and by shortening the bridge length of merocyanine molecules, we were able to map out the region of the $\beta$ curves in close proximity to the cyanine limit. Efforts are under way to synthesize merocyanines with stronger donor groups to induce larger ground state dipole moments and achieve the largest negative $\beta$ values for six, four and two methine bridges.

The work was performed in part by the Jet Propulsion Laboratory, California Institute of Technology, as part of its Center for Space Microelectronics Technology and was supported by the Ballistic Missiles Defense Initiative Organization, Innovative Science and Technology Office, through a contract with the National Aeronautics and Space Administration (NASA). Support at the Beckman Institute from the National Science Foundation (grant No. CHE-9 106689) and the Air Force Office of Scientific Research (grant No. 49620-93-1-0314) is gratefully acknowledged.

\section{Received, 23rd June 1994; Com. 4/03810J}

\section{Footnotes}

$\dagger$ Data for 5: mp 192-194 ${ }^{\circ} \mathrm{C} .{ }^{1} \mathrm{H}$ and Selected 1D TOCSY NMR (500 $\left.\mathrm{MHz} ; \mathrm{CD}_{3} \mathrm{COCD}_{3} ; J / \mathrm{Hz}\right) \delta 7.75(\mathrm{t}, J 13.1,1 \mathrm{H}), 7.64(\mathrm{~m}, 2 \mathrm{H}), 7.56$ $(\mathrm{m}, 2 \mathrm{H}), 7.54(\mathrm{t}, J 13.6,1 \mathrm{H}), 7.48(\mathrm{t}, J 12.5,1 \mathrm{H}), 7.41(\mathrm{~d}, J 12.31 \mathrm{H})$, $7.38(\mathrm{~d}, J 7.85,1 \mathrm{H}), 7.28(\mathrm{~m}, 1 \mathrm{H}), 7.05(\mathrm{~m}, 2 \mathrm{H}), 6.47(\mathrm{dd}, J 11.8,13.1$, $1 \mathrm{H}), 5.93(\mathrm{~d}, J 13.0,1 \mathrm{H}), 3.43(\mathrm{~s}, 3 \mathrm{H}), 1.62(\mathrm{~s}, 6 \mathrm{H})$. The compound was crystallized from benzene and one equivalent of benzene was present in the solid by elemental analysis and NMR. Anal. Calcd for $\mathrm{C}_{32} \mathrm{H}_{32} \mathrm{~N}_{2} \mathrm{O}_{2}: \mathrm{C}, 80.64 ; \mathrm{H}, 6.37 ; \mathrm{N}, 5.88$. Found $\mathrm{C}, 80.90 ; \mathrm{H}, 6.37 ; \mathrm{N}$, $5.83 \%$. High resolution EIMS, $m / z$ calc. $\mathrm{C}_{26} \mathrm{H}_{24} \mathrm{~N}_{2} \mathrm{O}_{2} 396.1838$, found 396.1834. Data for 4: mp ${ }^{180-181}{ }^{\circ} \mathrm{C}$. ' $\mathrm{H}$ NMR $\left(500 \mathrm{MHz} ; \mathrm{CD}_{2} \mathrm{Cl}_{2}\right.$; $J / \mathrm{Hz}) \delta 8.00(\mathrm{~d}, J 12.9,1 \mathrm{H}), 7.82(\mathrm{t}, J 13.3,1 \mathrm{H}), 7.48(\mathrm{t}, J 13.1,1 \mathrm{H})$, $7.33(\mathrm{t}, J 12.8,1 \mathrm{H}), 7.25(\mathrm{~m}, 2 \mathrm{H}), 7.02(\mathrm{~m}, 2 \mathrm{H}), 6.84(\mathrm{~d}, J 7.80,1 \mathrm{H})$, $6.41(\mathrm{t}, J 12.7,1 \mathrm{H}), 5.70(\mathrm{~d}, J 7.1,1 \mathrm{H}), 3.25(\mathrm{q}, J 7.1,4 \mathrm{H}), 3.29(\mathrm{~s}$, $3 \mathrm{H}), 1.60(\mathrm{~s}, 6 \mathrm{H})$. Anal. Calcd for $\mathrm{C}_{25} \mathrm{H}_{29} \mathrm{~N}_{3} \mathrm{O}_{3}: \mathrm{C}, 71.58 ; \mathrm{H}, 6.97 ; \mathrm{N}$, 10.02. Found: $\mathrm{C}, 71.49 ; \mathrm{H}, 6.99 ; \mathrm{N}, 10.06 \%$. High resolution EIMS, $\mathrm{m} / z$ calc. for $\mathrm{C}_{25} \mathrm{H}_{29} \mathrm{~N}_{3} \mathrm{O}_{3} 419.2209$, measured 419.2222. Data for 6: m.p. $207-210^{\circ} \mathrm{C}{ }^{~} \mathrm{H}$ NMR $\left(500 \mathrm{MHz} ; \mathrm{CD}_{2} \mathrm{Cl}_{2} ; \mathrm{J} / \mathrm{Hz}\right) \delta 7.80(\mathrm{~m}, 2 \mathrm{H})$ $7.67(\mathrm{~m}, 3 \mathrm{H}), 7.48(\mathrm{~d}, J 12.7,1 \mathrm{H}), 7.43(\mathrm{t}, J 13.1,1 \mathrm{H}), 7.26(\mathrm{~m}, 3 \mathrm{H})$, $7.00(\mathrm{t}, J 7.5,1 \mathrm{H}), 6.82(\mathrm{~d}, J 7.8,1 \mathrm{H}), 6.43(\mathrm{t}, J 12.7,1 \mathrm{H}), 5.67(\mathrm{~d}, J$ $12.7,1 \mathrm{H}), 3.27(\mathrm{~s}, 3 \mathrm{H}), 1.61(\mathrm{~s}, 6 \mathrm{H})$. Anal. Calcd for $\mathrm{C}_{26} \mathrm{H}_{23} \mathrm{NO}_{2}: \mathrm{C}$, $81.86 ; \mathrm{H}, 6.08 ; \mathrm{N}, 3.67$. Found $\mathrm{C}, 81.75 ; \mathrm{H}, 6.08 ; \mathrm{N}, 3.53 \%$. High resolution EIMS, $m / z$ calc. for $\mathrm{C}_{26} \mathrm{H}_{23} \mathrm{~N}_{1} \mathrm{O}_{2} ; 381.1729$, measured 381.1711 .

$\ddagger$ Crystal data: $\mathrm{C}_{26} \mathrm{H}_{23} \mathrm{NO}_{2}, M=381.5,163 \mathrm{~K}$, monoclinic, space group $P_{2} / n\left(\mathrm{C}_{2 h}\right.$; no. 14), $a=12.476(5), b=11.296(3), c=$ $15.203(5) \AA, \beta=107.49(2)^{\circ}, V=2043.6(12) \AA^{3}, Z=4, D_{\mathrm{c}}=1.240$ $\mathrm{g} \mathrm{cm}^{-3}$, Siemens P4 diffractometer, Mo-K $\alpha$ radiation $(\lambda=0.710730$ A), $\theta-2 \theta$ scan type $4.0<2 \theta<45.0^{\circ}, \mu(\mathrm{Mo}-\mathrm{K} \alpha),=0.078 \mathrm{~mm}^{-1} .2635$ reflections collected, 2334 with $F>2.0 \sigma(F), 332$ variables, $R=0.050$, $w R^{\prime}=0.050$, goodness of fit $=1.65$. Atomic coordinates, bond lengths and angles and thermal parameters have been deposited at the Cambridge Crystallographic Data Centre. See Information for Authors, Issue No. 1.

\section{References}

1 S. R. Marder, D. N. Beratan and L.-T. Cheng, Science, 1991, 252, 103

2 S. R. Marder, L.-T. Cheng and B. G. Tiemann, J. Chem. Soc., Chem. Commun., 1992, 672

3 S. R. Marder, J. W. Perry, G. Bourhill, C. B. Gorman, B. G. Tiemann and K. Mansour, Proc. Natl. Acad. Sci., USA, 1993, 90 , $11,297$.

4 G. Bourhill, J.-L. Brédas, L.-T. Cheng, S. R. Marder, F. Meyers, J. W. Perry and B. G. Tiemann, J. Am. Chem. Soc., 1994, 116, 2619.

5 L.-T. Cheng, W. Tam, S. H. Stevenson, G. R. Meredith, G. Rikken and S. R. Marder, J. Phys. Chem., 1991, 95, 10631.

6 L.-T. Cheng, W. Tam, S. R. Marder, A. E. Stiegman, G. Rikken and C. W. Spangler, J. Phys. Chem., 1991, 95, 10643.

7 C. R. Moylan, R. J. Twieg, V. Y. Lee, S. A. Swanson, K. M. Betterton and R. D. Miller, J. Am. Chem. Soc., 1993, 115, 12599.

8 K. D. Singer, J. E. Sohn, L. A. King, H. M. Gordon, H. E. Katz and C. W. Dirk, J. Opt. Soc. Am. B, 1989, 6, 1339.

9 B. F. Levine and C. G. Bethea, Appl. Phys. Lett., 1974, 24, 445.

$10 \mathrm{H}$. Ikeda, T. Sakai and K. Kawasaki 1991, 179, Japanese Patent No. 5.6, 551

11 J. L. Oudar and H. E. Le Person, Opt. Commun., 1977, 66, 2664.

$12 \mathrm{~J}$. Griffiths, Color and Constitution of Organic Molecules, Academic, London, 1976. 